\title{
CARACTERIZAÇÃO HISTOLÓGICA DE FÍGADOS BOVINOS COM FASCIOLOSE CRÔNICA
} \author{
Jose Romário de Carvalho ${ }^{3}$, Louisiane de Carvalho Nunes ${ }^{2}$ \\ 1 UFMG \\ 2 UFES \\ 3 FAFIA \\ Correspondência: Louisiane de Carvalho Nunes: louisianecn@yahoo.com.br
}

Fabiana Maria do Amaral Bravo de Paula', Dyeime Ribeiro de Sousa ${ }^{1}$, Anderson Barros Archanjo²,

RESUMO: A fasciolose bovina produz danos graves ao fígado e é causada pelo parasito Fasciola hepatica. Objetivou-se caracterizar as alterações histológicas do tecido hepático em bovinos com fasciolose crônica. Foram coletados 47 fígados de bovinos condenados por fasciolose e 12 fígados normais utilizados para controle. Foi feita a contagem de parasitos e coleta de cinco fragmentos de cada lobo, direito e esquerdo, dos fígados acometidos pela enfermidade, totalizando 235 amostras por lobo. O grupo controle foi coletado apenas um fragmento por fígado. Todo material foi fixado em formol a $10 \%$ e submetido ao processamento histológico. Foi feita a análise microscópica com base na distribuição da fibrose em graus 1,2 e 3 e no tipo e intensidade do infiltrado inflamatório. A avaliação estatística foi feita pelo método descritivo e pelo teste de Mann-Whitney com $5 \%$ de probabilidade. Não foi verificada diferença entre o número de parasitos por lobo hepático, porém o lobo esquerdo apresentou maior intensidade parasitária. A fibrose foi observada em todas as amostras prevalecendo a de grau 1. Houve diferença significativa entre fígados com $F$. hepatica e fígados normais quanto ao grau de fibrose, tanto para o lobo direito quanto para o esquerdo e entre estes. Verificou-se predominância de células mononucleadas de intensidade discreta. Houve diferença entre a intensidade do infiltrado inflamatório entre os lobos direito e esquerdo do fígado. A presença de eosinófilos também foi verificada, porém em menor quantidade. Conclui-se que a fibrose é alteração mais marcante em fígados cronicamente infectados por $F$. hepatica e o infiltrado inflamatório é predominantemente mononuclear discreto sendo estas lesões mais prevalentes no lobo esquerdo.

Palavras-chave: fibrose hepática; histologia; inflamação; trematoda

\section{HISTOLOGICAL CHARACTERIZATION OF THE BOVINE LIVER WITH CHRONIC FASCIOLIASIS}

ABSTRACT: Bovine fascioliasis produces severe damage to the liver and is caused by the parasite Fasciola hepatica. This study aimed to characterize the histological changes of the liver tissue with chronic fascioliasis in cattle. Were collected 47 bovine livers condemned for fascioliasis and 12 normal livers used to control. Counting parasites and collecting five fragments of each lobe, right and left livers affected by illness, totaling 235 samples per lobe was taken. The control group were collected only a fragment of liver. All material was fixed in $10 \%$ formalin and subjected to histological analysis. Microscopic analysis were based on the distribution of fibrosis in degrees 1, 2 and 3 and in the type and intensity of the inflammatory infiltrate. Statistical evaluation was taken by descriptive method and by Mann-Whitney test at $5 \%$ probability. No difference was observed between the number of parasites per lobe but the left lobe showed higher parasitic intensity. Fibrosis was observed in all samples and prevailed grade 1. There was significant difference between degree of fibrosis in the liver with fascioliasis and normal liver and between the hepatic lobes. The inflammatory infiltrate showed a predominance of mononuclear cells of discrete intensity. Was difference between the intensity of the inflammatory infiltrate between the right and left lobes of the liver. The presence of eosinophils was also observed, but at a lower amount. We conclude that fibrosis is most outstanding change in livers chronically infected with $F$. hepatica and the inflammatory infiltrate is predominantly mononuclear and discrete and these lesions are more prevalent in the left lobe.

Key Words: liver fibrosis; histology; inflammation; trematoda 


\section{INTRODUÇÃO}

A fasciolose é uma enfermidade que acomete o fígado e canais biliares de vários animais domésticos e silvestres, entre eles, ovinos, caprinos, búfalos, seres humanos e principalmente de bovinos. É causada por Fasciola hepatica, um trematódeo achatado dorsoventralmente de corpo foliáceo e com porção anterior em forma de cone (OLIVEIRA; SPÓSITO FILHA, 2009).

De acordo com Bostelmann et al. (2000) na fasciolose aguda, causada pelas formas imaturas dos parasitos, o grande número de trematodas no fígado leva a hepatomegalia, hiperemia do fígado, destruição do parênquima, insuficiência hepática, hemorragia na cavidade peritoneal, hepatite aguda hemorrágica, além da presença de um componente necrótico coagulativo, provavelmente relacionado a algum agente toxigênico liberado pelo parasito. Por outro lado, as formas adultas podem ocasionar fibrose e trauma severo no fígado e ductos biliares (HAROUN; HITLYER, 1986). As lesões fibróticas são as mais importantes alterações patológicas observadas no espaço porta de bovinos cronicamente infectados por F. hepatica e quanto maior o grau de lesão crônica maior é a distribuição da fibrose pelo parênquima (TRIVILIN, 2010).

Bostelmann et al. (2000) relataram ainda que as lesões causadas por $F$. hepatica aparecem a partir de nove semanas pós-infecção. No terço médio das paredes dos ductos biliares, nota-se espessamento com presença de formações acinares irregulares compostas por epitélio colunar alto, em geral infiltradas por linfócitos, plasmócitos, eosinófilos e mastócitos.

Embora a fibrose esteja presente nos quadros de fasciolose crônica, o mecanismo de formação deste processo ainda não está totalmente esclarecido
(TRIVILIN, 2010). Desta forma, Friedman e Carmichael (1998) informaram que é importante entender os eventos que levam a formação da fibrose a fim de identificar métodos terapêuticos que possam retardar seu processo de formação. Para isto, é necessário que haja identificação das estruturas, organismos e materiais secretados pelas células (WERNER et al., 2005) e a utilização de técnicas como a histoquímica podem ser importantes na precisão do diagnóstico histopatológico (ALVES et al., 2004). Tais estudos poderiam auxiliar na identificação do principal agente causador da fibrose hepática e estimular pesquisas de identificação de fatores químicos, celulares ou moleculares envolvidos (BARBOSA; ANDRADE, 2010).

Diante do exposto, o presente estudo objetivou caracterizar histologicamente as lesões hepáticas de bovinos com fasciolose crônica e verificar a relação entre as alterações encontradas.

\section{MATERIAL E MÉTODOS}

Para a realização do experimento, foram feitas três visitas técnicas no matadouro frigorífico de Atílio Vivacqua, ES durante o período de fevereiro a março de 2012, onde foram coletadas amostras de 47 fígados bovinos condenados por fasciolose e de 12 fígados normais.

No próprio matadouro, os fígados foram avaliados macroscopicamente para verificação da presença ou ausência de parasitos e divididos em dois lobos, direito e esquerdo, conforme estrutura anatômica. Cada lobo foi seccionado transversalmente, a cada um centímetro, para verificação e contagem dos parasitos.

Dos fígados condenados foram coletados cinco fragmentos de $2 \mathrm{~cm}^{2}$ de tecido hepático de cada lobo, direito e 
esquerdo, totalizando 470 subamostras, que corresponderam a outras 235 subamostras por lobo. Dos fígados normais, por determinação do matadouro frigorífico, foi coletado apenas um fragmento de $2 \mathrm{~cm}^{2}$ da porção média, totalizando 12 amostras que foram utilizadas como controle das análises microscópicas.

Todos os fragmentos foram devidamente identificados e fixados em solução de formol a $10 \%$ e direcionados ao Laboratório de Patologia Animal da UFES para avaliação microscópica.

No Laboratório de Patologia Animal todos os fragmentos foram recortados, armazenados em cassetes plásticos e submetidos ao processamento histológico de rotina para inclusão em parafina. Em seguida, foram submetidos à microtomia para a secção de cortes de três micrômetros de espessura que foram depositados em lâminas histológicas. Os cortes em lâminas foram corados pelo método de Hematoxilina e eosina (HE).

Para a avaliação histológica foram consideradas a distribuição da fibrose e o tipo e a intensidade do infiltrado inflamatório.

Para a avaliação da distribuição da fibrose utilizou-se os critérios estabelecidos por Oliveira, Souza e Andrade (2004) em que as alterações são divididas em graus, a saber: grau 1 (+), quando a fibrose aparece discretamente ao redor dos ductos não acometendo grandes extensões do parênquima hepático; grau $2(++)$, quando a fibrose é moderada formando septos fibrosos incompletos e grau 3 (+++), quando a fibrose é severa e revela septos fibrosos proeminentes que dividem 0 parênquima hepático em lóbulos.

Para a avaliação do infiltrado inflamatório foram utilizados critérios semelhantes aos descritos por Trivilin (2010) de forma semi-quantitativa com atribuição de escore de intensidade, a saber: discreto $(+)$, moderado $(++)$ e severo $(+++)$.

Todas as variáveis avaliadas (grau de fibrose, intensidade parasitária, infiltrado inflamatório) foram submetidas a estatística descritiva com os valores expressos em percentuais.

Com base nos cinco fragmentos das 47 amostras, totalizando 235 subamostras por lobo hepático, foi realizada avaliação do grau de fibrose, infiltrado inflamatório, comparando-se o lobo direito com o esquerdo pelo teste de Mann-Whitney a nível de $5 \%$ de probabilidade.

\section{RESULTADOS E DISCUSSÃO}

$\mathrm{Na}$ avaliação macroscópica dos fígados observou-se que 100\% (47/47) apresentaram fibrose caracterizada por depressão do parênquima e/ou espessamento da parede dos ductos biliares maiores. Em 80,85\% (38/47) foram encontrados parasitos no momento da coleta. No lobo direito observou-se formas juvenis e adultas do parasito variando de um a 16 e de um a 45 exemplares, respectivamente. No lobo esquerdo as formas jovens quantificadas variaram de um a 34 exemplares enquanto que as adultas de um a 45. Assim, não foi verificada diferença significativa $(p>0,05)$ entre $o$ número de parasitos por lobo hepático.

Em um estudo onde foram coletados 100 fragmentos do lobo esquerdo e lobo direito de fígados bovinos condenados por fasciolose, Trivilin et al. (2013) perceberam que em todas as amostras a intensidade de infiltrado inflamatório avaliadas acometiam mais do lobo hepático esquerdo, revelando que na fasciolose crônica, as lesões mais significativas concentram-se nesse lobo hepático. Ressaltaram ainda que, a inflamação observada variou de discreta a severa e 
sempre esteve associada à presença dos parasitos nos ductos biliares.

Apesar de Trivilin et al. (2013) não realizaram a contagem do número de parasitos encontrado nos ductos biliares, tais autores sugeriram que existe relação entre a presença de parasitos e lesões mais significativas.

Marcos et al. (2007) observaram 24 amostras de fígados bovinos frescos e concluíram que todos os fígados infectados pela $F$. hepatica tinham pelo menos um grau de fibrose hepática. $\mathrm{O}$ estudo também indicou que o número de fasciolas no fígado estava relacionado ao grau de fibrose, e que os casos positivos para cirrose apresentavam uma densidade parasitária maior que o grupo diagnosticado sem cirrose. Os autores afirmaram ainda que um número mínimo de 38 fasciolas pode representar um nível suficiente para causar cirrose hepática em bovinos.

Acredita-se que quanto mais rápido for realizado o diagnóstico da presença de $F$. hepatica em fígados bovinos o tratamento será mais efetivo evitando que sejam desenvolvidas lesões fibróticas severas bem como cirrose hepática. Bernardo et al. (2012) citaram que a utilização de técnicas utilizando coproantígenos pode detectar precocemente os animais infectados.

A análise histopatológica das lâminas coradas pelo método de hematoxilina-eosina (HE) revelou a presença de fibrose (Gráfico 1) em todas as amostras. De acordo com a classificação do grau de fibrose observou-se que, no lobo direito, $72,34 \% \quad(34 / 47)$ das amostras apresentavam fibrose grau 1 , $25,53 \%(12 / 47)$ grau 2 e 2,13\% (1/47) grau 3. No lobo esquerdo $55,32 \%$ (26/47) tiveram fibrose grau 1, 36,17\% (17/47) grau 2, 8,51\% (4/47) grau 3. Os resultados demonstraram prevalência de fibrose discreta.
Gráfico 1 - Distribuição dos graus de fibrose nos lobos direito e esquerdo de fígados bovinos infectados com Fascida hepatica L, Alegre, ES.
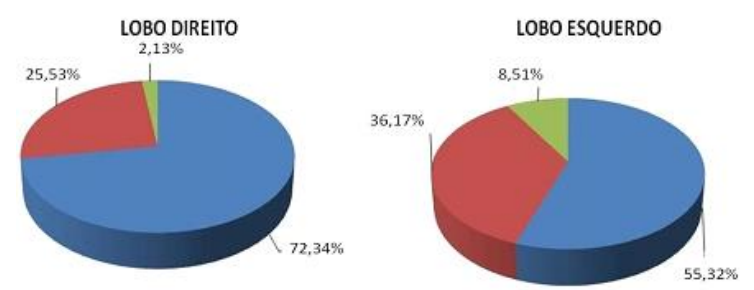

- Grau 1 Grau 2 Grau 3

A Figura 1 ilustra a distribuição da fibrose nos fígados com fasciolose.
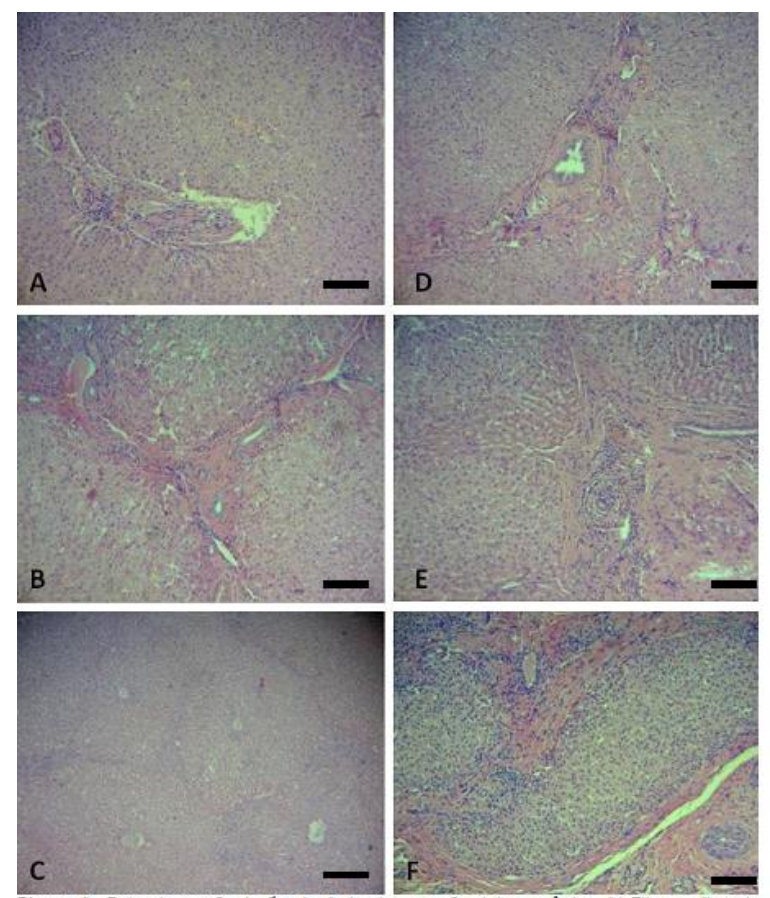

Figura 1 - Fotomicrografia de fígado de bovino com fasciolose crônica. A) Fibrose discret ao redor dos ductos biliares, Grau 1, Lobo direito, Barra=70 m; B) Fibros moderada com formação de septos incompletos, Grau 2, Lobo direito, Barra $=70 \mu \mathrm{m} ; C$ ) Fibrose $\infty \mathrm{m}$ septos proeminentes dividind o o parênquima en lóbulos, Grau 3, Lobo direito, Barra $=437,5 \mu \mathrm{m} ;$ D) Fibrose Grau 1, Lobo esquerdo, Barra $=67,8 \mu \mathrm{m} ; \mathrm{E}$ ) Fibrose Grau 2, Lobo esquerdo, Barra $=67,8 \mu \mathrm{m} ; F$ Fibrose Grau 3, Lobo esquerdo, Barra $=67,8 \mu \mathrm{m}$. Coloração de hematoxilina eosina.

Marcos et al. (2007) também encontraram lesões fibróticas em todos os fígados avaliados, entretanto, os dados de prevalência foram distintos sendo encontradas $17 \%$ das amostras com grau 1, 17\% grau 2 e $66 \%$ grau 3 . Estes autores verificaram predominância de lesões fibróticas mais graves. A diferença entre os resultados obtidos está relacionada a maior intensidade parasitária verificada por Marcos et al. (2007), bem como, aos 
diversos fatores epidemiológicos envolvidos na infecção dos bovinos.

Bostelmann et al. (2000) compararam fígados de bovinos, bubalinos e ovinos infectados por $F$. hepatica e constataram que o grau de fibrose da parede dos ductos biliares dos bovinos e bubalinos é maior que dos ovinos, devido a idade de abate dessas espécies serem diferentes. A idade de abate dos bovinos é de aproximadamente 36 meses, a dos bubalinos ocorre entre 24 a 30 meses e a dos ovinos é em torno de seis meses. Neste estudo foi possível identificar o parasito microscopicamente em apenas duas amostras hepáticas sendo uma com fibrose grau 1 e outra de grau 2. Devido ao baixo número de amostras não foi possível fazer uma correlação entre este achado e a existência de lesões fibróticas.

Diferentemente do que foi observado neste estudo, na análise histopatológica do fígado de uma alpaca adulta, macho, de idade desconhecida, a lesão mais proeminente foi uma extensa área de hiperplasia biliar e granulomas multifocais contendo ovos de parasitas que eram compatíveis com $F$. hepatica. Estes mesmos autores ainda citaram que a resposta fibrótica foi mínima na área de hiperplasia biliar, porém, era grande em torno das zonas de formação de granulomas (HAMIR; SMITH, 2002).

No entanto, segundo Trivilin (2010), as lesões fibróticas são as alterações mais importantes encontradas no espaço porta de bovinos cronicamente infectados por $F$. hepatica e observou que quanto maior o grau de lesão crônica, maior será a distribuição da fibrose pelo parênquima hepático.

Com base nos dados observados verificou-se diferença significativa $(p<0,05)$ entre fígados com $F$. hepatica e fígados normais quanto ao grau de fibrose, tanto para o lobo direito quanto para o esquerdo e entre estes (Tabela 1)1.

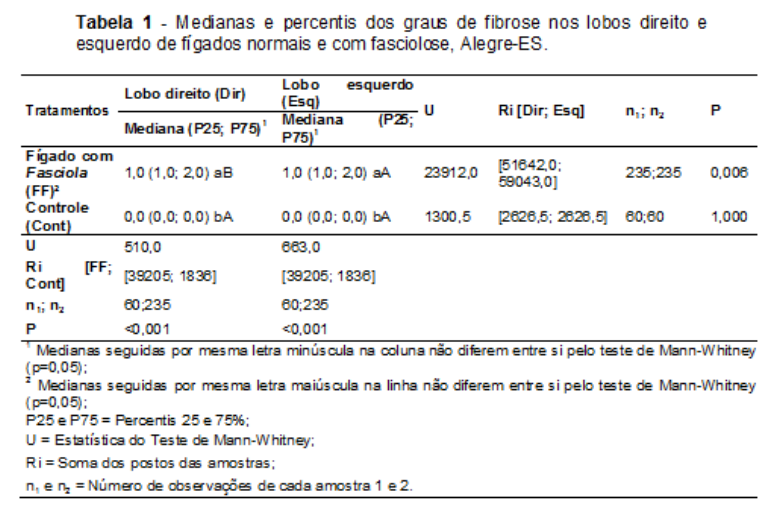

Conforme esperado, houve diferença significativa $(p<0,05)$ entre a fibrose existente nos fígados com fasciolose e os fígados normais, sendo que nos fígados normais, não houve deposição de tecido conjuntivo. Em relação a comparação entre os graus de fibrose por lobo hepático observou-se que, no lobo esquerdo, a fibrose foi mais significativa. Estes achados também foram observados por Trivilin (2010) que verificou que o lobo esquerdo era mais acometido pelas lesões fibróticas e vasculares que o lobo direito em estudo no Espírito Santo e por Tessele, Brum e Barros (2013) que encontraram lesões significativamente mais graves no lobo esquerdo quando comparada com 0 direito. Estes autores demonstraram atrofia severa do parênquima do lobo esquerdo em bovinos infectados por fasciolose no Rio Grande do Sul.

Em relação à avaliação do infiltrado inflamatório presente nos fígados observou-se predominância de células mononucleadas. No lobo esquerdo $61,70 \%$ (29/47) das amostras revelaram inflamação discreta, 25,53\% (12/47) moderada e $2,13 \% \quad(1 / 47)$ severa. Entretanto, em 10,64\% (5/47) das amostras deste lobo não houve qualquer lesão inflamatória. No lobo direito $63,83 \%(30 / 47)$ das amostras revelaram infiltrado inflamatório discreto, $19,15 \%$ (9/47) moderado e nenhuma amostra revelou inflamação severa. Em $17,20 \%$ (8/47) das amostras do lobo 
sérios danos hepáticos (ORTEGA et al., 2002).

A presença de eosinófilos também foi verificada no infiltrado inflamatório dos fígados avaliados neste estudo, porém em menor quantidade. No lobo direito, apenas 8,51\% (4/47) das amostras revelaram infiltrado predominantemente eosinofílico, enquanto que, no lobo esquerdo, estas células foram verificadas em 12,76\% (6/47) das amostras.

Em humanos com fasciolose, Marcos et al. (2008) afirmaram que a hipereosinofilia pode acontecer na metade ou final das infecções agudas e a eosinofilia leve em casos de infecção precoce. A metade dos pacientes crônicos pode ter ausência de eosinofilia. Por isso, estes autores sugeriram que a contagem normal de eosinófilos em muitos pacientes não pode ser utilizada para fins de rastreio, em áreas endêmicas.

$\mathrm{Em}$ ratos o infiltrado inflamatório ao redor dos túneis migratórios variou de escasso a moderado e consistiu, principalmente, da infiltração maciça de eosinófilos e neutrófilos, alguns macrófagos, plasmócitos e linfócitos (BEYTUT; AKÇA; GÖKÇE, 2011). Bostelmann et al. (2000) verificaram infiltração por linfócitos, plasmócitos, neutrófilos e eosinófilos de intensidade moderada a intensa, com presença de mastócitos em fígados parasitados por $F$. hepatica de bovinos, bubalinos e ovinos.

\section{CONCLUSÃO}

A fibrose é alteração mais marcante em fígados cronicamente infectados por $F$. hepatica e é mais evidente no lobo hepático esquerdo. $\mathrm{O}$ infiltrado inflamatório é predominantemente mononuclear discreto e mais prevalente no lobo esquerdo.

\section{AGRADECIMENTOS}

À CAPES (Coordenação de Aperfeiçoamento de Pessoal de Nível Superior) pelo apoio financeiro ao projeto.

\section{REFERÊNCIAS}

ALVES, V.A.F.; LEANDRO, L.O.; VASSALLO, J et al. Controle de qualidade interlaboratorial em imuno-histoquímica: citoceratinas e receptor de estrógeno como modelos. Jornal Brasileiro de Patologia, v. 40, n.3, p.175-183, 2004.

BARBOSA, V.L.C.; ANDRADE, Z.A. Capillaria hepatica - induced septal fibrosis in rats: a contribution to the study of liver fibrogenesis.

Revista da Sociedade Brasileira de Medicina Tropical, v.43, n.5, p.504-507, 2010.

BERNARDO, C.C.; AVELAR, B.R.; IGNATCHI, M.D.C. et al. Kit comercial de ELISA para a detecção de coproantígenos e exame coproparasitológico em bovinos com fígados condenados por fasciolose. Ciência Rural, v.42, n.11, p.2025, 2012.

BEYTUT, E.; AKÇA, A.; GÖKÇE, H.I.

Pathological and immunohistochemical evaluation of the effects of interferon gamma (IFN-y) and aminoguanidine in rats experimentally infected with Fasciola hepatica.

Turkish Journal of Veterinary \& Animal Sciences, v.35, n.4, p.243-253, 2011.

BOSTELMANN, S.C.W.; LUZ, E.; SOCCOL, V.T. et al. Histopatologia comparativa em fígados de bovinos, bubalinos e ovinos infectados por Fasciola hepatica. Archives of Veterinary Science, v.5, n.4, p.95-100, 2000.

FRIEDMAN, W.E.; CARMICHAEL, J.S., Heterochrony and developmental innovation: evolution of female gametophyte ontogeny in Gnetum. Evolution, v.52, p.1016-1030, 1998.

HAMIR, A.N.; SMITH, B.B. Severe Biliary Hyperplasia Associated with Liver Fluke Infection in an Adult Alpaca. Veterinary Pathology, v. 35, n.5, p.592-594, 2002.

HAROUN, E.T.M.; HITLYER, G.V. Resistance to fascioliasis - a review. Veterinary Patology, v.20, n.1-3, p.63-93, 1986.

MARCOS, L.A.; TAGLE, M.; TERASHIMA, A. et al. Natural history, clinicoradiologic correlates, and response to triclabendazole in acute massive fascioliasis. The American Journal of Tropical Medicine and Hygiene, v.78, n.2, p.222-227, 2008. 
MARCOS, L.A.; YI, P.; MACHICADO, A. et al., A. Hepatic fibrosis and Fasciola hepatica infection in cattle. Journal of Helminthology, v.81, n.4, p.381-386, 2007.

OLIVEIRA, L.; SOUZA, M.M.; ANDRADE, Z. Capillaria hepatica-induced hepatic fibrosis in rats: paradoxical effect of repeated infections. Revista da Sociedade Brasileira de Medicina Tropical, v.37, n.2, p.123-127, 2004.

OLIVEIRA, S.M.; SPÓSITO FILHA, E. Fasciolose Hepática. Biológico, v.71, n.1, p.5-7, 2009.

ORTEGA, J.; PERIS, B.; CORPA, J.M. et al. Fasciolosis experimental ovina: efecto de reinfecciones y tratamiento en la respuesta inmune humoral y celular local. Sociedad Española de Ovinotecnia y Caprinotecnia, p.733-739, 2002.

TESSELE, B.; BRUM, J.S.; BARROS, C.S.L. Lesões parasitárias encontradas em bovinos abatidos para consumo humano. Pesquisa Veterinária Brasileira, v.33, n.7, p.873-889, 2013.

TRIVILIN, L.O; SOUSA, D.R.; NUNES, L.C. et al. Imunofenotipagem da resposta inflamatória em fígados de bovinos cronicamente e naturalmente infectados por Fasciola hepática. Revista Brasileira de Medicina Veterinária, v.35, n.1, p.41-47, 2013.

TRIVILIN, L.O. Avaliação histopatológica e imunoistoquímica de fígados de bovinos cronicamente infectados por Fasciola hepatica. 2010. Alegre, 100f. Dissertação (Mestrado em Ciências Veterinárias) Programa de Pós-graduação em Ciências Veterinárias, Universidade Federal do Espírito Santo.

WERNER, B.; CAMPOS, AC.; NADJI, M. et al. Uso prático da imuno-histoquímica em patologia cirúrgica. Jornal Brasileiro de Patologia e Medicina Laboratorial, v.41, p.353-364, 2005. 